\title{
A Rare Case of Successive Pregnancies in a Woman with Complex Cyanotic Congenital Heart Disease after Glenn Palliation
}

\author{
Marwa Mohamed, Shazia Mohsin, Merna Atiyah, Ahmed Al Zahrani, Khalid Alnajashi* \\ Prince Sultan Cardiac Center, Riyadh, KSA \\ Email: ^Kalnajashi@pscc.med.sa
}

How to cite this paper: Mohamed, M., Mohsin, S., Atiyah, M., Al Zahrani, A. and Alnajashi, K. (2017) A Rare Case of Successive Pregnancies in a Woman with Complex Cyanotic Congenital Heart Disease after Glenn Palliation. World Journal of Cardiovascular Diseases, 7, 423-428.

https://doi.org/10.4236/wjcd.2017.712040

Received: November 7, 2017

Accepted: December 4, 2017

Published: December 7, 2017

Copyright $\odot 2017$ by authors and Scientific Research Publishing Inc. This work is licensed under the Creative Commons Attribution International License (CC BY 4.0).

http://creativecommons.org/licenses/by/4.0/

\begin{abstract}
The bidirectional Glenn procedure is an integral step in the optimal palliation for single ventricular physiology in many forms of complex congenital heart disease. An increasing number of women who have undergone this connection in childhood are now reaching childbearing years. Low pulmonary blood flow and volume over load on the single ventricle pose several problems during pregnancy. We are reporting a 33-year-old lady with congenital tricuspid atresia and mild pulmonary stenosis who had late Bidirectional Glenn procedure with pulmonary forward flow and later underwent six successful pregnancies, with delivery of six low birth weight babies with no reported complications.
\end{abstract}

\section{Keywords}

Glenn Palliation, Pregnancy, Tricuspid Atresia

\section{Introduction}

Congenital heart disease (CHD) occurs in about $1 \%$ of live newborns, and 50\% of these children are female. The improvement of cardiac surgery for CHD as well as the post-surgical care has resulted in a large population of adult women with $\mathrm{CHD}$, and majority of them are willing to get pregnant. Pregnancy in these women is associated with cardiovascular complications, which occur in about $10 \%$ of pregnancies [1] [2].

The Bidirectional Glenn (BDG) procedure is an integral step in the optimal palliation of Single ventricle (SV) Physiology. The systemic venous return in BDG from inferior vena cava and pulmonary veins reaches the single atrium (post septectomy) and the SV ejects the systemic circulation as well as a part of pulmonary blood flow $(\mathrm{PBF})$; the rest of $\mathrm{PBF}$ is flowing passively from Superior 
vena cava to Right Pulmonary Artery. The goal of this procedure is ventricular deloading which has been associated with advantageous changes to the SV including reduction in the ventricular end-diastolic volume, and favorable geometry changes of ventricular wall thickness [3].

Completion of Fontan after BDG has led to improvement of SV palliation survival [4]; therefore the number of women who reach child bearing age is increasing, and successful pregnancies after Fontan have been reported [5]. Achievement of successful pregnancies after BDG is still a possibility, but rarely reported. We report a case of BDG with forward pulmonary blood flow who underwent six successive pregnancies with successful outcome.

\section{Case Presentation}

A 31-year-old Saudi woman was diagnosed to have congenital heart disease (CHD) at age of 3 months, in terms of tricuspid atresia (TA), hypoplastic right ventricle (HRV), pulmonary stenosis (PS), large atrial septal defect (ASD) and small ventricular septal defect (VSD) with normally related great arteries, based on cardiac catheterization. She was kept under follow up in the outpatient department and her cardiac status remained balanced for several years. Subsequent cardiac catheterization was done at age of 11 years, to assess her hemodynamics, which showed mean pulmonary artery pressure of $12 \mathrm{mmHg}$, and oxygen saturation of $85 \%$. Angiogram showed good size pulmonary arteries, restrictive VSD and good sized ASD. She underwent Glenn operation at age of 12 years, with smooth post-operative course and she was discharged in good condition. There were no justifications mentioned in the casenotes at that time for not proceeding to single stage Fontan completion.

Unfortunately she lost follow up after BDG procedure, and later showed up in adult congenital heart disease clinic at our center at 31 years of age, with five successful pregnancies. This time she was five months pregnant with her sixth baby. A summary of her pregnancies is given in Table 1. All deliveries were conducted in local hospital normally with no reported adverse events related to

Table 1. Summary of the six pregnancies.

\begin{tabular}{|c|c|c|c|c|c|c|c|}
\hline $\begin{array}{c}\text { Age } \\
\text { of patient }\end{array}$ & $\begin{array}{l}\text { Complications } \\
\text { during pregnancy }\end{array}$ & $\begin{array}{c}\text { Gestational age } \\
\text { at delivery }\end{array}$ & $\begin{array}{l}\text { Mode of } \\
\text { delivery }\end{array}$ & $\begin{array}{l}\text { Baby } \\
\text { gender }\end{array}$ & $\begin{array}{l}\text { Baby status } \\
\text { after birth }\end{array}$ & $\begin{array}{c}\text { Birth } \\
\text { weight (g) }\end{array}$ & $\begin{array}{l}\text { Complication } \\
\text { after delivery }\end{array}$ \\
\hline 18 & None & 27 weeks & Spontaneous Vaginal Delivery & Male & Good & 1500 & $\begin{array}{l}\text { Neonatal intensive } \\
\text { Care unit admission }\end{array}$ \\
\hline 19 & None & Term & Spontaneous Vaginal Delivery & Male & Good & 1800 & None \\
\hline 24 & None & Term & Spontaneous Vaginal Delivery & Female & Good & 1800 & None \\
\hline 29 & None & Term & Spontaneous Vaginal Delivery & Female & Good & 1800 & None \\
\hline 31 & none & Term & Spontaneous Vaginal Delivery & male & Good & 2200 & None \\
\hline
\end{tabular}


her cardiac condition. All babies were low birth weight and had no congenital heart disease. Her clinical condition during all pregnancies remained unchanged, and completely asymptomatic. Her clinical assessment during this visit revealed that her exercise capacity was maintained within normal, and her saturation ranged between $85 \%-87 \%$ in upper limb. Her electrocardiogram showed sinus rhythm with heart rate of 71 beat per minute and left axis deviation. 24-Hour Holter monitoring revealed that her basic rhythm was sinus rhythm, with average heart rate of 78 beat $/ \mathrm{min}$, lowest heart rate 51 beat $/ \mathrm{min}$, maximum heart rate $140 \mathrm{beat} / \mathrm{min}$ and no significant arrhythmias were noted. Echocardiogram showed mild left ventricular dilatation with mildly reduced systolic function. Ejection fraction about $45 \%-50 \%$. Mild to moderate mitral regurgitation (most likely due to dilated mitral valve annulus). Glenn anastomosis with laminar flow and good atrial communication. Her hemoglobin was $16 \mathrm{~g} / \mathrm{dl}$. Other blood investigations were within normal limits. She delivered a full term baby boy weighing 2200 grams via SVD with no peri and postpartum complications. Her last clinic visit 3 months after her delivery showed no deterioration in her clinical condition.

\section{Discussion}

The BDG is a step towards final palliation for SV physiology with the aim to volume under load the SV by decreasing the ventricular end diastolic pressure and ventricular wall thickness. BDG with pulmonary forward flow (PFF) has been advocated in literature to be associated with improved oxygen saturation, enhancement of pulmonary artery growth, but it could also mitigate the above mentioned advantages of BDG. However, proponents of forward flow in BDG claim it to decrease the morbidity, as Al-Ghamdi et al. suggested to keep the forward flow in sub optimal candidates for a future Fontan similar to our patient [6] [7].

There is ample literature evidence regarding successful pregnancies in post Fontan SV but very few with BDG.

In pregnancy, normal physiological changes like increased blood volume (BV), decreased hematocrit, decreased systemic vascular resistance (SVR), increased heart rate and increased cardiac output (CO), increased concentration of coagulation factors, fibrinogen and platelet adhesiveness as well as decreased fibrinogen can present maternal and fetal threat to patients with SV resulting in preterm deliveries, still birth ( $16 \%$ - 57\% respectively), Maternal heart failure, significant maternal arrhythmia [8] [9] [10].

In our patient the systemic venous return from inferior vena cava and pulmonary veins reaches the single atrium (post septectomy) and the SV ejects the systemic circulation as well as part of pulmonary blood flow (PBF), the rest of PBF is flowing passively from Superior vena cava to Right Pulmonary Artery. Hence the physiological effects of the pregnancy imposed more burden on our patient in terms of less PBF, cardiac output (CO) and lower oxygen saturation. 
She already had borderline ventricular dysfunction, yet her saturations and hemoglobin $(\mathrm{Hb})$ were optimal. In patients like ours, tolerance to anemia is very limited therefore, $\mathrm{Hb}$ has to be optimal to ensure adequate oxygen delivery to maintain $\mathrm{CO}$ as described by Broberg et al. [11].

According to Association of European Pediatric Cardiology the preferred mode of delivery in CHD is instrumental assisted vaginal delivery as it reduces the chances of complications with either spontaneous vaginal delivery (SVD) and Caesarean section (CS) [10]. The Valsalva method in SVD can decrease the $\mathrm{PBF}$ followed by increase in venous return which can be detrimental in a patient whose PBF is dependent on venous flow, like our patient. At the same time, General anesthesia and positive pressure ventilation in CS can decrease the SVR and increase Right to left shunt, and decrease the PBF, thereby aggravating hypoxemia. So the optimal mode of delivery was opted for in our patient which was assisted vaginal delivery. Our patient has a pulmonary forward flow in addition to BDG which actually helped her with the physiological stresses described above.

$\mathrm{Al}$ Ghamdi et al. and the other proponents of pulmonary forward flow stated that the forward flow helps maintain the oxygen saturation and $\mathrm{CO}$ as compared to patients with no forward flow. Wendling et al. [12], reported a similar case with successful outcome but their mode of delivery was CS due to demand of patient.

A 23-year-old was reported by Dib et al. with history of multiple miscarriages, presented with murmur cyanosis and erythrocytosis. She was diagnosed to have hypoplastic right ventricle with pulmonary stenosis like our patient and was operated for BDG with forward flow and completed successful full term pregnancy with normal weight baby later [13].

To further support our case as mentioned before there are numerous literature evidence of successful pregnancies post Fontan, indicating possibility of live births after Fontan palliation. Collin et al. reported 282 pregnancies with SV with no death, $74 \%$ had vaginal deliveries, $25 \%$ had maternal complications mostly arrhythmias few had obstetric complications like preterm and intrauterine growth retardation [14].

In the end we would like to emphasize the fact that pregnancies are high risk, for both mother and baby in this group of congenital heart disease, however due to social and cultural pressures in our part of region it's very difficult to convince our patients to not to conceive, thereby, by keeping all the management aspects in mind a successful planned fully monitored pregnancy can be carried out in specialized multidisciplinary centers.

\section{Conclusion}

Achievement of successful pregnancy after Glenn is feasible but rarely reported and could be completed without major sequel. Tertiary cardiac center with advanced obstetric and neonatal care and high risk programs is crucial. There is no 
enough evidence supporting that the Glenn with an additional pulmonary forward flow is better than Fontan completion but it could be a good option especially in those patients with difficult access to proper medical care. Up to our knowledge, this is the first case to be reported from this region with bidirectional Glenn anastomosis and successful pregnancies.

\section{Ethical Statement}

This study did not receive any grants.

All authors have no conflict of interest.

The patient had given her consent for the case to be published.

\section{References}

[1] Siu, S.C., Sermer, M., Colman, J.M., Alvarez, A.N., Mercier, L.A., Morton, B.C., et al. (2001) Cardiac Disease in Pregnancy (CARPREG) Investigators. Prospective Multicenter Study of Pregnancy Outcomes in Women with Heart Disease. Circulation, 104, 515-521. https://doi.org/10.1161/hc3001.093437

[2] Khairy, P., Ouyang, D.W., Fernandes, S.M., Lee-Parritz, A., Economy, K.E. and Landzberg, M.J. (2006) Pregnancy Outcomes in Women with Congenital Heart Disease. Circulation, 113, 517-524. https://doi.org/10.1161/CIRCULATIONAHA.105.589655

[3] Freedom, R.M., Nykanen, D. and Benson, L.N. (1998) The Physiology of the Bidirectional Cavopulmonary Connection. The Annals of Thoracic Surgery, 66, 664-667. https://doi.org/10.1016/S0003-4975(98)00618-3

[4] Pundi, K.N., Johnson, J.N., Dearani, J.A., Pundi, K.N., Li, Z., Hinck, C.A., et al. (2015) 40-Year Follow-Up after the Fontan Operation: Long-Term Outcomes of 1,052 Patients. Journal of the American College of Cardiology, 66, 1700-1710. https://doi.org/10.1016/j.jacc.2015.07.065

[5] Gouton, M., Nizard, J., Patel, M., Sassolas, F., Jimenez, M., Radojevic, J., et al. (2015) Maternal and Fetal Outcomes of Pregnancy with Fontan Circulation: A Multicentric Observational Study. International Journal of Cardiology, 187, 84-89. https://doi.org/10.1016/j.ijcard.2015.03.344

[6] Alghamdi, A.A. (2015) Bidirectional Glenn with Additional Pulmonary Blood Flow: Systematic Review and Evidence-Based Recommendations. Journal of Cardiac Surgery, 30, 724-730. https://doi.org/10.1111/jocs.12592

[7] Ferns, S.J., EI Zein, C., Multani, K., Sajan, I., Subramanian, S., Polimenakos, A.C., et al. (2013) Is Additional Pulsatile Pulmonary Blood Flow Beneficial to Patients with Bidirectional Glenn? The Journal of Thoracic and Cardiovascular Surgery, 145, 451-454. https://doi.org/10.1016/j.jtcvs.2012.11.027

[8] The Criteria Committee of the New York Heart Association (1994) Nomenclature and Criteria for Diagnosis of Diseases of the Heart and Great Vessels. 9th Edition, Little, Brown \& Co, Boston, Mass, 253-256.

[9] Regitz-Zagrosek, V., Blomstrom Lundqvist, C., Borghi, C., Cifkova, R., Ferreira, R., Foidart, J.M., et al. (2011) ESC Guidelines on the Management of Cardiovascular Diseases during Pregnancy: The Task Force on the Management of Cardiovascular Diseases during Pregnancy of the European Society of Cardiology (ESC). European Society of Gynecology (ESG); Association for European Paediatric Cardiology (AEPC); German Society for Gender Medicine (DGesGM). European Heart Jour- 
nal, 32, 3147-3197. https://doi.org/10.1093/eurheartj/ehr218

[10] Baumgartner, H., Bonhoeffer, P., De Groot, N.M., de Haan, F., Deanfield, J.E., Galie, N., et al. (2010) Task Force on the Management of Grown up Congenital Heart Disease of the European Society of Cardiology (ESC); Association for European Pediatric Cardiology (AEPC). Esc Guidelines for the Management of Grown up Congenital Heart Disease (2010). European Heart Journal, 31, 2915-2957.

https://doi.org/10.1093/eurheartj/ehq249

[11] Broberg, C.S., Jayaweera, A.R., Diller, G.P., Prasad, S.K., Thein, S.L., Bax, B.E., et al. (2011) Seeking Optimal Relation between Oxygen Saturation and Hemoglobin Concentration in Adults with Cyanosis from Congenital Heart Disease. American Journal of Cardiology, 107, 595-599. https://doi.org/10.1016/j.amjcard.2010.10.019

[12] Adam, L., Wendling, M.D., Aaron Seller, M.D. and Everett Peterson, M.D. (2012) Case Report of a Parturient with Cyanotic Congenital Heart Disease Palliated with a Glenn Procedure. Journal of Clinical Anesthesia, 24, 586-589.

https://doi.org/10.1016/j.jclinane.2012.03.008

[13] Dib, C., Araoz, P.A., Davies, N.P., Dearani, J.A. and Ammash, N.M. (2012) Case report: Hypoplastic Right-Heart Syndrome Presenting as Multiple Miscarriages. Texas Heart Institute Journal, 39, 249-254.

[14] Collins 2nd, R.T., Chang, D., Sandlin, A., Goudie, A. and Robbins, J.M. (2017) National In-Hospital Outcome of Pregnancy in Women with Single Ventricle with Congenital Heart Disease. American Journal of Cardiology, 119, 1106-1110. https://doi.org/10.1016/j.amjcard.2016.12.015 